\title{
Medo e Conjuração: desfazendo o parentesco na Amazônia
}

\author{
Marcelo Moura Silva ${ }^{1}$ \\ ${ }^{1}$ Museu Nacional, Rio de Janeiro, RJ, Brasil
}




\section{Resumo}

A proposta deste artigo é promover uma análise das dinâmicas do parentesco na Amazônia que tome os procedimentos que o desfazem, ou a decisão de não o fazer, como índices da influência de um método de administração da alteridade, característico das sociedades das terras baixas da América do Sul. As múltiplas modulações possíveis que o sujeito ameríndio pode assumir na ontologia multinaturalista, aqui, nos levam a questões que permitem uma análise que conecta as alianças interespecíficas do ambiente perspectivista com as relações interpessoais dos processos do parentesco e as redes intercomunitárias que interligam as diferentes comunidades na Amazônia, como procedimentos que atuam dentro de um mesmo complexo cosmopolítico.

Palavras-chave: Parentesco. Multinaturalismo. Cosmopolítica. Identificação. Diferenciação.

\section{Abstract}

The purpose of this article is to promote an analysis of the kinship dynamics in the Amazon taking the procedures that undo it, or the decision not to do it, as indices of the influence of the otherness administration method, characteristic of South America lowlands societies. The multiple possible modulations that the Amerindian subject can assume in the multinaturalist ontology, here, lead us to questions that allow an analysis that connects the interspecific alliances of the perspectivist environment with the interpersonal relations of the kinship processes and the intercommunal networks that connect the different communities in the Amazon, as procedures that operate within the same cosmopolitical complex.

Keywords: Kinship. Multinaturalism. Cosmopolitcs. Identification. Differentiation. 


\section{Introdução}

Medo. Medo. Medo. Medo. Medo. Medo.

Cada um guarda mais o seu segredo, A sua mão fechada, a sua boca aberta.

O seu peito deserta, sua mão parada, Lacrada e selada, E molhada de medo.

(Na hora do Almoço - BELCHIOR)

s questões que inspiram este artigo são aquelas colocadas pelas
formulações próprias aos povos ameríndios sobre o estatuto do humano, a condição de pessoa e a posição de sujeito, principalmente em ocasiões da vida indígena em que estas se desestabilizam, permitindo sua contestação e revogação. Essa instabilidade é comumente exacerbada em momentos críticos identificados na infância, na caça, na guerra, no xamanismo, na doença e na morte e procedem, em muitos casos, por meio da destruição dos vínculos identitários que sustentam a estrutura do parentesco que compõe grupo. Ou seja, a destruição do parentesco nos momentos de incerteza ou perda da consciência de si.

O que tentarei desenvolver a seguir são algumas reflexões sobre os efeitos dessas desestabilizações, as fissuras e os dissensos que podem engendrar, e as formas de incidência destas nas dinâmicas sociais em que atuam. As múltiplas modulações possíveis que o sujeito ameríndio pode assumir na ontologia multinaturalista, aqui, nos levam a questões que permitem uma análise que conecta as alianças interespecíficas do ambiente perspectivista com as relações interpessoais dos processos do parentesco e as redes intercomunitárias que relacionam as diferentes 
comunidades na Amazônia, como procedimentos que atuam dentro de um mesmo complexo cosmopolítico.

Na canção que nos serve de epígrafe, o poeta cearense faz ir junto o ato de comer, as relações de parentesco e o sentimento de medo, desenvolvidos cotidianamente ao redor da mesa do almoço. Não muito diferente fazem os ameríndios, que, por sua vez, o fazem ao redor de suas fogueiras. É comendo e vivendo junto que se fazem os parentes e é em relação ao parentesco que se desenvolve o medo. Os medos, na canção e nas elaborações ameríndias, funcionam em sentidos paralelos e versam sobre o receio da possibilidade de submissão, a representação forçada das perspectivas sob o signo de uma unidade englobante. O medo do Estado, ou antes: o medo como sentimento contra-o-estado e conjuração do Um.

A subjetividade unívoca do sujeito da canção teme a captura da identidade que tem consigo mesmo pela unidade da família, temendo reproduzir em si aquilo que identifica como sendo próprio do outro, e o outro é o parente, uma versão negativada de si próprio: o exterior do Eu é o parentesco. Teme a abertura ao outro, ainda que esse outro seja um parente próximo, guardando segredos, mantendo a mão fechada e a boca aberta - "ganhar sem perder, gozar sem partilhar" (LÉVI-STRAUSS, 1982, p. 537) - a antítese do que se espera de uma relação nas economias do dom. Paisagem do individualismo com a qual nós, "modernos", estamos acostumados.

Já para a subjetividade equívoca e polivalente ameríndia, como demonstrou Viveiros de Castro (2011), o medo e o desejo se voltam para a alteridade radical, pois a existência dessa figura é a condição de possibilidade fundamental para a formação do socius e da noção de pessoa na Amazônia. Dessa maneira, o ameríndio tem medo de ter a perspectiva capturada pelo Outro, o que resultaria na perda da capacidade de reconhecer os vínculos de parentesco desejados e fundamentais para a personitude do sujeito. A posição de sujeito na Amazônia é suscetível a sucumbir à preensão ontológica em um mau encontro com a alteridade animal, quando o Outro é fundamentalmente um não parente. Entretanto, o desejo pelos vínculos sociais habilitados pelo parentesco não é exclusividade dos seres humanos e o outroanimal amedrontador não faz mais do que buscar parentes para si. 
Dessa maneira, o diálogo desenvolvido entre as ontologias díspares tem como idioma-base a afinidade potencial:

Se o Outro, para nós, emerge do indeterminado ao ser posto como um irmão, isto é, como alguém que se liga a mim por estarmos em idêntica relação a um termo superior comum (o pai, a nação, a igreja, um ideal), o Outro amazônico será determinado como cunhado, alteridade horizontal e imanente. (VIVEIROS DE CASTRO, 2013, p. 423)

A afinidade potencial é, segundo Viveiros de Castro, o modelo referencial sob o qual se constroem as outras formas de relação na Amazônia, incluindo as que regem a vida cotidiana no interior dos grupos locais. Partindo de um diálogo com as elaborações teóricas de Roy Wagner sobre o dado e o construído, o autor pode afirmar que na imaginação conceitual multinaturalista é a aliança que assume o polo de dado, sendo esta hierarquicamente mais significativa em relação à consanguinidade. A consubstancialidade entre parentes não é dada, e assim, precisa ser construída ativamente - por meio da comensalidade e do convívio cotidiano, compartilhando alimentos e o desejo pelo parentesco - contra o fundo geral de afinidade de onde emergem os sujeitos. Da afirmação que o parentesco precisa ser construído, podemos inferir que ele também pode e, em alguns casos, precisa ser desfeito, ou antes, que ele pode (e mais uma vez, precise) não ser construído.

A proposta do trabalho é promover uma análise das dinâmicas do parentesco na Amazônia que tome os procedimentos que o desfazem, ou a decisão de não fazê-lo, como índices da influência de um método de administração da alteridade característico das sociedades das terras baixas da América do sul. Tal práxis, por sua vez, está enraizada na ontologia multinaturalista que afirma a "[...] naturalidade da variação, a variação como natureza" (VIVEIROS DE CASTRO, 2015, p. 69, grifo no original). O objetivo é demonstrar como se atualiza, nas diferentes relações que envolvem o sujeito ameríndio, uma conceituação que tende a escapar de cristalizações e que se sustentam em uma metafísica contra-o-Um, canibal e disjuntiva. O que pretendo sugerir é que podemos encontrar nos procedimentos que desfazem o parentesco as reverberações dessa ideologia e, assim, entender esses processos 
como momentos de um agenciamento cosmopolítico amplo. Dessa forma, reunir em uma argumentação orquestrada as reflexões sobre o perspectivismo, as composições sociopolíticas que caracterizam as sociedades contra-o-estado e os mecanismos de produção do parentesco amazônico.

Assim o que se propõe é, sobretudo, uma análise do parentesco amazônico, mas tomando o assunto pelo "avesso", como sugere Marina Vanzolini (2015). O que se pretende com essa inversão é observar nos atos que desfazem o parentesco as dinâmicas que conectam os múltiplos limites do interior da comunidade e a alteridade exterior, humana e não humana. É por meio da captura da perspectiva por outrem e das fissuras comunitárias e intercomunitárias produzidas pela feitiçaria, pelo xamanismo e pela guerra, que o parentesco é desfeito, mas são essas rupturas que garantem a endoconsistência e a capacidade de reprodução desses grupos:

Sem o influxo perigoso das forças e das formas que povoam o exterior do socius, este fatalmente falece, por carência de diferença. Para poder viver a seu gosto - "viver bem", como se diz que os índios gostam de dizer - é preciso primeiro gostar de viver perigosamente. (VIVEIROS DE CASTRO, 2011, p. 889)

Dessa forma, a proposta seguirá os desenvolvimentos de Viveiros de Castro sobre os aspectos característicos das configurações do parentesco na Amazônia. Na sessão adiante, percorreremos o caminho teórico proposto pelo autor para a compreensão dessas estruturas, identificando os pressupostos sobre os quais basearemos nossa análise. Em seguida, visitaremos etnografias de diferentes contextos amazônicos que podem sustentar, em suas respectivas exposições, as hipóteses aqui buscadas.

Para explicitar os procedimentos de fabricação do parentesco e a conjuração da condição indeterminada do sujeito na criança observaremos o processo de construção da pessoa-parente via comensalidade e cuidado entre os Wari' e os Piro. Para a compreensão dos efeitos disjuntivos internos aos grupos, observaremos a feitiçaria entre os Aweti e a forma como ela fragmenta as relações de parentesco no ambiente multicomunitário xinguano. Por fim, para uma análise das relações intercomunitárias que produzem um ambiente sócio- 
político atomizado, tomaremos como interlocutores os Yanomami. Observaremos como as guerras e alianças, que dinamizam as relações entre as comunidades e entre as diferentes modulações de humanidade que povoam a cosmologia, também gerem a alteridade pelo idioma do parentesco.

\section{Fundamentos da Incerteza}

O estudo do parentesco precisou, para avançar na compreensão dessas práticas no contexto amazônico, promover uma verdadeira transformação nos métodos clássicos da abordagem sobre o tema. Uma geração de etnólogos amazonistas foi responsável pela reabilitação, após um período de ostracismo, desses estudos que sempre estiveram entre as principais agendas da disciplina. É a partir dos desenvolvimentos desse momento específico da etnologia que promoveremos a análise que se segue. Focaremos nas considerações de Viveiros de Castro sobre as dificuldades da reprodução de determinados esquemas conceituais que a antropologia sustentava até então nas análises dos sistemas de parentesco, tendo sido necessário repensá-los para habilitar sua aplicação aos estudos sobre os povos das terras baixas da América do sul.

Inicialmente, cabe notar que tanto nas elaborações sobre o perspectivismo ameríndio quanto nas que privilegiam o tema do parentesco, o autor se defronta com alguns dualismos que povoam o pensamento ocidental, através de uma complexificação dos valores e posições de cada termo desses dualismos. O faz para dar conta de contextos ontológicos díspares - moderno e ameríndio - de modo a revelar a insustentabilidade prática dessas distinções, principalmente, por meio das diferenças incompatíveis que caracterizam a relação entre os dois polos da análise. Em “Perspectivismo e multinaturalismo na América Indígena" (VIVEIROS DE CASTRO, 2013, p. 347), o par natureza x cultura sofre todo tipo de torção na análise simétrica a que é submetido. O mesmo ocorre na relação entre os conceitos de consanguinidade e afinidade em "Atualização e contra-efetuação do virtual" (VIVEIROS DE CASTRO, 2013, p. 403), emergindo, após o mergulho promovido pelo autor, completamente revolvidos. 
Pretendendo perseguir a construção de uma "teoria geral da sociabilidade amazônica", Viveiros de Castro (2013, p. 404) sugere que a noção de afinidade é, na Amazônia indígena, o modelo principal sobre o qual são construídas as outras modulações relacionais possíveis e, assim, as convenções da consanguinidade privilegiadas no modelo ocidental do parentesco são sobrepostas e progressivamente eclipsadas por seu oposto no contexto ameríndio. Baseando-se em materiais etnográficos que testemunhavam estruturas sociais organizadas em grupos locais de cognação, endogâmicos, onde prescrições correlatas às linhas de descendência e filiação não são mobilizadas para o estabelecimento de alianças matrimoniais, o autor sugere que a afinidade virtual não é apenas um componente entre outros no sistema do parentesco amazônico, mas a condição mesma de sua possibilidade, fonte de onde emerge a afinidade atual e a consanguinidade. Operando como valor genérico, “[...] ela é a dimensão de virtualidade de que o parentesco é o processo de atualização" (VIVEIROS DE CASTRO, 2013, p. 412).

O autor pode afirmá-lo, sobretudo, em função da ampla atuação das figuras do sogro e do cunhado nas narrativas mitológicas sobre as origens dos povos da Amazônia. Uma situação comum nessas narrativas é o protagonista ser seduzido e atraído a algum encontro amoroso por uma mulher que posteriormente revela-se pertencente a uma humanidade-animal. O sogro ou os cunhados do estrangeiro o fazem executar provas e tarefas desagradáveis e perigosas, demonstrando o ethos de meta-hostilidade característica que envolve as relações entre os afins potenciais, principalmente entre aqueles que não pertencem aos círculos mais próximos de sociabilidade. Além disso, desse pequeno esquema mítico, estruturado em suas mais variadas formas na região, podemos observar também outro aspecto fundamental dessas dinâmicas sociais, que é sua extensão até os vínculos relacionais estabelecidos com outros seres e subjetividades - animais, espíritos, objetos, plantas, formações geológicas, fenômenos meteorológicos, concreções astronômicas, etc. - que povoam e atuam no cosmos amazônico.

Viveiros de Castro aborda, por meio do conceito de perspectivismo, os métodos de administração da alteridade voltados aos seres não humanos incorporados nas negociações do socius ameríndio. Nessa ontologia, 
as características culturais supostamente próprias à humanidade são compartilhadas por animais e outros seres da "natureza". Deslocada para o domínio do universal, a cultura é o substrato primordial sobre o qual a natureza se constitui. Aqui, Viveiros de Castro propõe o termo multinaturalismo para caracterizar tal esquema ontológico: uma mesma cultura e modulações múltiplas da natureza ativadas nos diferentes corpos-perspectivas.

Nas narrativas sobre o tempo mítico as personagens são humano-animais que se envolvem em atividades caracteristicamente humanas, como guerras e casamentos, onde um evento desencadeia o processo de diferenciação corporal dos seres, que a partir daí passam a assumir as formas que são visíveis na "natureza" do tempo pósmítico. A corporalidade diferenciada - ou o multinaturalismo - altera substancialmente o mundo experimentado pela humanidade que a assume. Vendo-se como humanos, os peixes veriam os humanos como onças, ou seja, predadores; ao mesmo passo que a onça veria os humanos como porcos, suas presas. Nesse contexto, é a metafísica da predação que fornece o escopo da sociabilidade entre as diferentes humanidades virtuais, em um "mundo onde toda diferença é política, porque toda relação é social" (VIVEIROS DE CASTRO, 2015, p. 54).

O processo de diferenciação, passado no tempo mítico, é a atualização das virtualidades já presentes na condição humana generalizada que povoava o mundo primordial. Nesse tempo, as diferenças entre os viventes eram internas e intensivas, de modo que a diferenciação é um processo de atualização dos devires-espécies amalgamados no fundo virtual de indiscernibilidade do qual participam as protossubjetividades, relacionadas por meio da afinidade potencial generalizada. Porém, a especiação nunca é completamente realizada e, a qualquer momento, os corpos e as perspectivas podem ser submetidos a todo tipo de transformação: “[...] a humanidade de fundo é menos um predicado de todos os seres que uma incerteza constitutiva sobre os predicados de qualquer ser" (VIVEIROS DE CASTRO, 2011, p. 894). Das transformações possíveis da perspectiva e do corpo decorre o medo de um sujeito interromper seu pertencimento à humanidade e assim, perder a capacidade de reconhecer seus parentes. 
A fabricação do corpo humano do recém-nascido e da criança é colocada em prática para garantir o pertencimento do novo membro à humanidade da qual participam seus congêneres. A consubstancialidade entre parentes próximos precisa ser buscada e construída, e é contra a possibilidade - sempre dada - do estabelecimento de alianças interespecíficas, intensivas, contranaturais e cosmopolíticas, que se produzem as alianças extensivas, culturais e sociopolíticas (VIVEIROS DE CASTRO, 2015, p. 189). Ainda assim, mesmo estabelecidas as relações de identidade que posicionam os sujeitos em seus grupos, existe o risco constante de que um Outro submeta a perspectiva do sujeito à sua, já que o choque entre perspectivas não admite que duas modulações distintas de humanidade vejam a si mesmas ao mesmo tempo como humanas, sendo preciso que uma delas abandone sua posição. O modelo prototípico da captura de perspectiva é o que envolve o caçador solitário, vulnerável (com medo) na floresta, que deve atuar observando sua conduta para conjurar a possibilidade de ser submetido à perspectiva de outrem. Tal fato o atrairia para uma parentela animal, de modo que não conseguiria mais reconhecer seus parentes, fazendo-o, como em muitos casos, cometer atos de violência contra eles. Não pertencendo mais à perspectiva congênere humana, passa a enxergar seus parentes como presas.

O que pretendo ressaltar no argumento de Viveiros de Castro, para os propósitos desse artigo, é que o fundo virtual de afinidade e indiscernibilidade entre os agentes subjetivos precisa ser contraefetuado pelos processos de diferenciação para a produção do socius amazônico. Este se fundamenta no desejo ativamente perseguido de reproduzir uma estrutura social de identidade intra-humana, firmada pelos grupos locais de cognação. O processo de extrair progressivamente os caracteres de afinidade potencial na relação efetiva é realizado nas relações interpessoais no interior do grupo cognático para a reprodução do parentesco. O mesmo método é utilizado na construção da subjetividade nos indivíduos que emergem do fundo de afinidade virtual. Ademais, é o procedimento básico para estabelecer relações com grupos vizinhos, parceiros de troca e ritual. No esquema sociopolítico de projeção concêntrica, vemos a consanguinização dos afins nos 
círculos mais próximos da sociabilidade ao mesmo tempo em que se observa a afinização dos que povoam os círculos distantes. Um ambiente amplamente administrado pelo idioma da afinidade: "O Outro, em suma, é primeiro de tudo um afim" (VIVEIROS DE CASTRO, 2013, p. 416). Assim, as configurações sociais da região se desenvolvem em um cosmos povoado por múltiplas humanidades em corpos distintos, que gerem suas relações a partir de um dado universal de afinidade virtual, tanto no nível da construção da pessoa quanto na produção do grupo local e nas relações deste com outros grupos, humanos e não humanos.

No diagrama que o autor propõe para a compreensão do desequilíbrio perpétuo da estrutura do parentesco, vemos duas linhas paralelas onde uma descreve o movimento de escalonamento em que a afinidade virtual é progressivamente suplantada por linhas sucessivas de identificação - a contraefetuação do virtual - e outra linha, que redireciona o trânsito a seu ponto de origem, reintroduzindo a afinidade nos esquemas relacionais, garantindo a produção de uma estrutura orientada, cíclica e capaz de se reproduzir (VIVEIROS DE CASTRO, 2013, p. 440). Entretanto - o autor ressalta repetidas vezes - a linha que desce não é a mesma linha que sobe. A linha descendente segue removendo as camadas da afinidade generalizada dos seres indiscerníveis no tempo mítico, produzindo nesse percurso as diferenciações específicas. O mesmo esquema serve para descrever o processo de parentesco que precisa produzir corpos de parentes e garantir que se conjurem as possibilidades de perda da posição de sujeito nas relações com outras subjetividades. Além disso, serve também para descrever as relações intercomunitárias e o concentrismo sociopolítico, que de fora para dentro, introduz alteridade para gerar identidade. A identidade - entre espécies, parentes e parceiros - precisa ser ativamente produzida, mesmo não sendo nunca plenamente alcançada. O autor vai além ao sugerir que a identidade só pode existir a partir da alteridade, sendo a primeira "[...] um caso particular da diferença [...]" (VIVEIROS DE CASTRO, 2013, p. 422), no qual esta é quase completamente anulada.

Em todo o percurso, porém, a linha de identificação está sujeita a ser interrompida por processos de reafinização. Os laços de consanguinidade que se estabelecem entre parentes próximos podem e, - o ponto que 
persigo aqui - precisam ser desfeitos em algum momento - durante a vida ou na morte -, de forma a reproduzir o movimento cíclico do qual depende a existência do sistema. A destruição do parentesco procede reintroduzindo o Outro na dinâmica de reprodução do grupo.

O processo de identificação no parentesco amazônico pode se perpetuar a partir da incorporação da alteridade que atua fundando o sistema e garantindo sua fluência vital, já que é o que promove o desequilíbrio criativo da estrutura de diferenciação e identificação sucessivas. As guerras e as redes matrimoniais, a feitiçaria e o xamanismo, as capturas de perspectiva e a construção (ou não) do parentesco, conectam e separam, em síntese disjuntiva, o interior e o exterior da pessoa e da comunidade às redes de relacionamento intercomunitárias e interespecíficas: são momentos de um mesmo agenciamento cosmopolítico amplo, que tem na alteridade a origem e o destino. Uma metafísica contra-o-Um, antissolipsista, que afirma a impossibilidade de uma existência não referenciada e antirrelacional; que não pressupõe identidade e a conjura ativamente em todos os planos relacionais, mesmo que isso signifique a produção de fissuras no interior da pessoa, dos grupos locais e do complexo de sociabilidade do qual participam.

Dessa forma, pretende-se expor a seguir alguns movimentos da "linha que sobe" no diagrama de Viveiros de Castro e que é responsável por todo tipo de fissuras no socius amazônico, direcionando as relações no sentido do polo de afinidade e, a partir dela, até a hostilidade que caracteriza a relação entre afins. A construção do parentesco através da fabricação da pessoa e o papel crucial desempenhado pela afinidade nesse processo serão observados entre os Piro e os Wari'. Veremos como o medo provocado pela possibilidade de um recémnascido firmar alianças com outras parentelas pode resultar no não aparentamento da criança e de que forma aparentar-se depende de momentos controlados de destruição do parentesco. Entre os Aweti, veremos como se engendram hostilidades que atuam na reafinização dos consanguíneos no interior do grupo local, principalmente aqueles que se revelam feiticeiros: e feiticeiro, como se sabe no Xingu, não é gente (VANZOLINI, 2015). Entre os Yanomami, veremos a cura xamânica 
conjurar no enfermo a possibilidade de um parentesco transespecífico, por meio das relações entre os xamãs e os xapiri que pressupõem um processo de consanguinização, além de observar como a recusa do parentesco exogâmico e a reafirmação das identidades intragrupais condicionam a relação ritual entres os grupos.

\section{Movimentos da Linha que Sobe}

Em "Making Kin out of Others in Amazônia" (VILAÇA, 2002), Vilaça parte das reflexões de Joanna Overing (OVERING, 1999) que apontavam para a importância - nos estudos sobre os povos amazônicos - de uma mudança de foco que voltasse as atenções para os assuntos da vida cotidiana e doméstica, onde a comensalidade e convivialidade produzem os corpos-parentes. Vilaça aceita essa sugestão, mas argumenta em contraposição que a produção do parentesco não pode estar exclusivamente relacionada ao contexto doméstico e intracomunitário, já que a mobilização do exterior, por meio de um diálogo interespecífico constante, é condição de possibilidade fundamental para o dinamismo dessa produção. Propondo uma análise que conecta as relações de parentesco com o esquema cosmológico, a autora demonstra como esses dois domínios da prática social se retroalimentam entre os Wari'. Das elaborações nativas sobre a construção da pessoa e a incerteza sobre a condição de humanidade do recém-nascido, a autora pode concluir que, concebida como uma posição essencialmente transitória, a personitude é produzida a partir de um amplo universo de subjetividades que escapam dos domínios do grupo cognático.

A centralidade do corpo nas ontologias ameríndias, onde as disposições físicas condicionam a perspectiva, é o fio condutor da análise do esquema do parentesco Wari' promovido pela autora. Assumindo o fato de que a consanguinidade entre pais e filhos não é garantida pela concepção da criança, sendo necessária sua fabricação contínua através do cuidado mútuo e da comensalidade, Vilaça observa que a produção do parentesco Wari' se dá pela coabitação e, que apesar da tendência endogâmica, evitam nas relações internas ao grupo o uso de terminologias de afinidade. As relações de afinidade, marcadas por uma 
hostilidade característica entre as partes, precisam ser substituídas por relações entre consanguíneos no interior do grupo de modo a permitir o convívio. O parentesco é produzido pela proximidade e, sobretudo, pelo desejo de produzi-lo contra a afinidade.

Em um contexto onde as relações sociais determinam as substâncias, o corpo do indivíduo recém-nascido precisa ser produzido como um corpo-parente. Emergindo do fundo virtual de afinidade característico da preexistência, a criança está sujeita à influência de subjetividades animais que poderão capturá-la para o seu convívio. A alimentação, aqui, é um processo crítico. Do fato de que se alimentam de animais de caça, que nos postulados da ontologia multinaturalista possuem o que nós modernos chamaríamos de alma, a comida revela-se essencialmente perigosa. A vingança, dentro da metafísica da predação, é uma possibilidade constante e pode levar animais a atacar e matar as pessoas, momento em que os espíritos-animais "devoram" suas almas. Porém, esse processo, explica um xamã Wari' (VILAÇA, 2002, p. 354), demonstra a vontade revelada pelas subjetividades animais de produzirem parentesco para si. Tal desejo é revelado, também, nos períodos de doença, quando a predação da alma humana por espíritos indica a possibilidade da mudança de perspectiva, alimentando nas pessoas o desejo de viver com seus parentes animais. A predação desdobrada no xamanismo, na feitiçaria e na guerra - e o parentesco - desdobrado em afinidade e consanguinidade - são os idiomas que regem as relações entre as subjetividades que compõem a cosmologia Wari'.

Vilaça sugere, então, que os procedimentos característicos da couvade, agenciados em função do nascimento de um novo membro do grupo, se voltam para o medo da captura da criança por outras humanidades, já que a construção do corpo do recém-nascido é, primeiramente, a fabricação de um corpo humano em contraposição a um corpo animal. A interdição de determinados alimentos de caça é observada de modo a impedir o adoecimento da criança, o que a transformaria gradualmente em um animal, como testemunhou a autora no veredito de um xamã, que depois de encontrar pelos e larvas durante a tentativa de cura de uma criança, sugere que ela já 
estava no processo de se transformar em macaco, que teria na morte o acabamento da transformação. O processo de formação do vínculo de parentesco interno ao grupo local não é pensado, pelos Wari', sem a contrapartida do desejo expressado por outras humanidades, igualmente sociais, de também acumular parentes para si. Dessa forma, a produção do parentesco intra-humano é possibilitada pela obliteração de uma possível aliança interespecífica a ser efetuada pelo sujeito ainda indeterminado na criança.

Peter Gow (1997) observa procedimentos semelhantes entre os Piro, que podem iluminar ainda mais o ponto que perseguimos aqui. $\mathrm{O}$ autor parte de uma análise sobre um mito Piro que narra a origem da humanidade, estruturado de maneira semelhante ao esquema mítico que apresentamos no início desse trabalho - um casamento interespecífico entre afins potenciais, que se reverte em uma história de hostilidade e vingança. Do mito o autor pode afirmar que “[...] tudo que nós precisamos saber sobre o parentesco dos Piro está contido na narração dessa curta história, porque tudo que eles precisam saber está contido nesse evento" (GOW, 1997, p. 44). Assim, Gow (1997) caracteriza o parentesco piro como um momento de um amplo processo de transformação de Outros em Humanos e de Humanos em Outros, iniciado no tempo mítico e que se prolonga até os dias de hoje. A transformação inicia com a fabricação da posição de humano na criança, construída à revelia do fundo de afinidade virtual de que participam os seres. Por meio do cuidado e alimentação dispensados a ela pelo grupo, e da emergência espontânea de determinadas qualidades que indicam a capacidade da criança de reconhecer e se relacionar com seus congêneres - principalmente o nshinikanchi, glosado pelo autor como "mente, inteligência, memória, respeito, amor" - é que se produz um corpo-parente.

O casamento bestial entre uma mulher e um jaguar, no mito, revela-se perigoso pela incompatibilidade de costumes e afecções entre as duas modulações de humanidade distintas. Uma relação estável entre afins potenciais provenientes de grupos diferentes, aqui, aparece como improvável, mesmo com a ativação do processo de consanguinização pelo casamento e convívio, indicando na mitologia o fundamento para a 
preferência pela endogamia. O casamento deve ser buscado no interior do grupo, e assim, paradoxalmente entre consanguíneos. Porém, as dinâmicas de diferenciação internas garantem que tais casamentos não sejam incestuosos.

Dando atenção à "sobreimportância" que as capacidades da visão e da linguagem têm para a noção de humanidade piro, o autor pode sugerir que a incerteza sobre a condição humana do feto decorre da impossibilidade de vê-los e de sua incapacidade de fala. Gow nos mostra que "um feto é manewlu, 'aquilo que está tendo um corpo feito', 'aquilo que está sendo incorporado'”. Ele é o paciente da ação verbal manewata, "dar forma substancial a", "fazer um corpo para" (GOW, 1997, p. 47). A soma de partes do homem (que pode ser mais de um) e da mulher - o sêmen e o sangue menstrual - produzem o corpo do bebê durante todo o processo de gestação, mas é só na emergência da criança que seus congêneres podem finalmente responder a pergunta: É um bebê humano?

Dessa forma, o corpo do recém-nascido precisa ser inspecionado pelas pessoas que assistem seu nascimento. Parentes em potencial, atentos ao menor sinal de disposições animais, poderão responder sobre a humanidade ou não da criança. Esse é um momento crucial, para os Piro e para a presente análise, já que o veredito negativo sobre sua condição humana resulta no abandono da criança e a não fabricação do parentesco com ela. A criança é deixada para ser levada por seus parentes animais, já que, como vimos no mito citado acima, o convívio entre "estrangeiros" pode se revelar perigoso. Se não produz aliança com humanos, o fará com os animais. Se a existência do corpo pressupõe perspectiva e esta não pode existir sem relação, a parentela animal que captura a criança abandonada conjura a possibilidade de uma existência não referenciada, sendo necessário pensar todo indivíduo atrelado à sua sociedade, todo sujeito a um grupo, toda vida a uma comunidade, todo um ao seu múltiplo.

No caso de confirmação da humanidade da criança, o veredito precisar ser legitimado em outro momento crucial: o corte do cordão umbilical. Além do corpo, o cordão umbilical e a placenta são constituintes do ser recém-nascido e sinais de seu desenvolvimento 
"[...] a partir de sua condição prévia de auto-involução dentro do útero materno" (GOW, 1997, p. 48). Ainda no útero, segundo Gow, a criança é pensada como não possuindo interior e exterior, já que está embrulhada em si mesma por seu "duplo": a placenta, seu Outro imediato. Ao nascer, a criança precisa ser separada desse Outro pelo corte do cordão umbilical e passa a ter interioridade, mesmo que ainda vazia. Este vazio logo será preenchido por seus parentes. Primeiramente através do aleitamento e, depois do desmame, pelo nshinikanchi_que emerge na criança a partir da satisfação de suas necessidades pelos cuidados dos parentes. É essa satisfação que aflora na criança o desejo por seus parentes, e assim, o desenvolvimento de seu nshinikanch.

O processo que envolve o corte do cordão, detalhado por Gow, é interessante para os propósitos dessa análise, já que é um indicativo da necessidade de desfazer o parentesco para que suas dinâmicas possam ser reproduzidas. O parto da criança é acompanhado por seus parentes mais próximos, genitores e avós, que ao confirmarem a humanidade da criança, precisam que esta seja legitimada pelo grupo. Assim, o pai do recém-nascido deve buscar dentro do grupo, - ou seja, entre seus parentes - alguém disposto a admitir a incerteza sobre a condição de humano do neném, mesmo com a primeira confirmação dos mais próximos. Isso significa que durante esse processo o parentesco estabelecido entre os membros do grupo local, e mais precisamente entre o pai da criança e o cortador do cordão, precisa ser desfeito de maneira a permitir que seja um não parente a legitimar a condição humana do neófito, habilitando-o, finalmente, a ser fabricado como parente pelo grupo. É somente um não parente que poderá cortar o cordão umbilical, definitivamente separando a criança de seu Outro. Entretanto, o grupo local expressa, em seu interior, a negação das relações de afinidade entre seus membros por meio da interdição de terminologias que indicam tal condição. Gow (1997, p. 49) diz:

A convocação de um cortador de cordão umbilical é, assim, um momento delicado, pois o pai da criança deve ir até alguém, dirigir-se a essa pessoa por um determinado termo de parentesco, para logo em seguida negar o parentesco suposto pelo termo, com o pedido de que corte o cordão do recém-surgido, isto é, de um ser em via de se tornar parente 
do pai. Tão logo o ato é consumado, tudo se estabiliza, pois seus protagonistas entram em uma rede de novas relações baseadas nele.

Se tomarmos o diagrama das linhas de identificação e diferenciação de Viveiros de Castro para analisar essa situação poderíamos dizer que, entre o nascimento e o corte do cordão umbilical, acontece todo tipo de flutuação em um zigue-zague entre as linhas. Vejamos: o primeiro movimento, a confirmação pelos parentes próximos da humanidade da criança, indica a identificação entre a criança e seus genitores, de modo a extrair a afinidade dessa relação, "descendo" do fundo geral de afinidade virtual em direção à consubstancialidade. No segundo momento do processo, vemos a promoção de duas novas diferenciações, e "subimos" novamente no diagrama: o retorno da incerteza da humanidade da criança, além da destruição do parentesco prévio entre o pai e o cortador do cordão que, amalgamados pela cognação do grupo, são reafinizados no processo. O terceiro momento, o corte do cordão propriamente dito, também opera dois movimentos na linha: um que conjura a possibilidade da afinidade animal na criança, situando-a novamente no "mesmo nível" de seus genitores, e outro que reconsanguiniza o pai e o cortador, ambos os movimentos "descendo" na direção da identificação, agora em uma nova relação engendrada a partir da criança com quem passam a ter uma espécie de superidentificação: um "hiperparentesco" nas palavras de Gow (GOW, 1997). Todo esse "sobe e desce" é demonstrativo da afirmação de Viveiros de Castro (2013, p. 421): “[...] que a consanguinidade e a afinidade amazônicas não são categorias taxonomicamente descontínuas, mas zonas de intensidade de um mesmo campo escalar".

Nesse pequeno esquema, podemos ter uma visão completa da estrutura cíclica, que precisa reintroduzir a alteridade exterior no seio da identificação do grupo, desfazendo o parentesco momentaneamente, para refazê-lo logo em seguida, na produção de um novo parente. A destruição do parentesco é então, condição fundamental da reprodução de seu próprio domínio, que através do desejo pelo convívio intrahumano produz corpos-parentes e ao mesmo tempo nega a possibilidade da concomitância da posição de sujeito entre humanos e não humanos. 
A subjetividade animal da criança é contraefetuada pelas dinâmicas do parentesco, garantindo-lhe a condição de humano ao mesmo tempo que reafirma a posição do grupo. Um processo onde a identidade intrahumana é ativamente buscada. Mas a identidade em excesso é perigosa e precisa ser contrabalanceada por outros métodos de diferenciação.

A feitiçaria Aweti nos permite avançar ainda mais nessa direção. Tais práticas se desenvolvem no interior do ethos pacifista da sociedade xinguana, que postula a necessidade do abandono das posturas de hostilidade entre os povos que o compartilham. A observação e manutenção desse repertório moral são condições imprescindíveis àqueles que almejam seguir compartilhando da posição de humano, de modo que "[...] ser gente, nos termos aweti, é não ficar bravo" (VANZOLINI, 2013, p. 342, grifos no original). Porém, como vimos anteriormente, no pensamento ameríndio a humanidade é uma posição instável e constantemente ameaçada que precisa ser reafirmada ao longo da vida, em um esforço contínuo. A feitiçaria é um dos vetores de desestabilização que atua reintroduzindo a afinidade e a hostilidade, ao desestabilizar a cosanguinidade no interior dos grupos de parentesco e ao redistribuir as subjetividades no quadro cosmopolítico em que estão inseridos. Temyzotu_termo aweti que designa "[...] tanto o desejo de obter aquilo que pertence ao outro quanto o medo de perder aquilo que é seu [...]" (VANZOLINI, 2013, p. 341), é o sentimento que impulsiona os feitiços e as rupturas. Condensando o díptico ciúme-inveja, é a afecção a ser evitada entre parentes, sendo o tipo de postura característica nas relações com a alteridade: sempre evitada e, contudo, paradoxalmente desejada. A partir dos "maus sentimentos entre parentes" uma postura de hostilidade se desenvolve, desestabilizando os laços sedimentados pelo parentesco.

A análise de Vanzolini volta a enfatizar a centralidade do corpo para a sociabilidade ameríndia. As teorias Aweti sobre a causalidade das doenças e mortes coloca a atuação de um agressor como razão principal desses eventos. Atingidos pelas flechas dos espíritos kat ou por feitiços promovidos por outros xinguanos, os doentes são submetidos a um processo perigoso, que através da consubstancialização com seus algozes, suspende sua condição de humano temporariamente, se for 
possível a cura, ou definitivamente em caso de morte. Um xamã poderá tentar - com o auxílio dos espíritos que carrega consigo - promover a reintegração do duplo do doente a seu corpo, afastando as causas da enfermidade e trazendo de volta a pessoa ao convívio de seus parentes. Se falhar, os casos de doenças provocadas pelas flechas de kat (kat u'wyp) resultam na transformação do doente que passaria a viver entre os espíritos como um parente. Já nas mortes provocadas por feitiçaria - e, como se sabe, "só se morre de feitiço no alto Xingu" (VANZOLINI, 2013, p. 344) - os mortos seguem para sua aldeia no céu e para a parentela que o recebe. Adoecer, antes de qualquer outra coisa, é passar por um processo de identificação com outra modulação da humanidade, é pendular entre as possíveis corporalidades e vislumbrar outras perspectivas. A morte não encerra o corpo em sua inércia e individualidade, mas reconecta a pessoa em outro esquema relacional.

Entre a agressão do feiticeiro e a cura do xamã habitam distintas legiões de entidades espirituais mobilizadas na contenda por cada um dos lados. O xamã Aweti, atuando para garantir a reprodução do grupo mobiliza os espíritos kat dos quais é dono para encontrar e retirar do corpo do doente as flechas de outros kat ou as flechas lançadas por um feiticeiro. Consideradas como elementos corporais do feiticeiro, suas flechas tupiat quando lançadas, ou "amarradas", aos corpos de suas vítimas produzem uma identificação consubstancial perigosa para ambos. Através do feitiço o corpo da vítima se abre a um canal que a deixa vulnerável à atuação do feiticeiro, mas é esse mesmo vaso comunicante que será utilizado pelos parentes do morto que, utilizando partes do cadáver da vitima, poderão provocar malefícios ao agressor através da feitiçaria de vingança (VANZOLINI, 2013, p. 351).

Vemos que assim o feitiço ativa processos de diferenciação e identificação, de modo que nos permite entendê-los como momentos interligados em um processo mais amplo. Ao lançar um feitiço contra um parente, o agressor reintroduz a hostilidade e diferença no interior do grupo consanguinizado por alianças matrimoniais e rituais. Desse modo, ao desfazer os vínculos de parentesco, reafirma a diferença no centro de um processo que busca ativamente a identificação. A figura do feiticeiro é colocada em direta contraposição à condição de humanidade, 
de modo que uma acusação de feitiço reafirma a identificação entre os humanos propriamente ditos, os diferenciando daqueles que negam a moralidade condicionante dessa posição. A introdução da alteridade entre parentes via feitiço atua contra a identificação positiva que os diferencia dos não humanos. Entretanto, toda identificação excessiva é perigosa, como na gemelaridade e na profunda conexão entre o corpo dos pais e o da criança em seus primeiros meses de vida. Desse modo, um novo processo de diferenciação precisa ser ativado, que efetue, ou atualize, o que o parentesco contraefetua.

De maneira similar ao corte de cordão umbilical entre os Piro, vemos nas dinâmicas da feitiçaria Aweti uma sequência de momentos que ilustra a necessidade da destruição dos laços de parentesco para a garantia da reprodução de seu próprio domínio, porém agora com a geração de efeitos disjuntivos na sociabilidade intra-humana, evitados na situação anterior. No primeiro momento de diferenciação, o adoecimento produz a separação do enfermo-vítima de seu duplo e de sua posição de sujeito, gerando a quebra dos vínculos de parentesco e o conectando a outra humanidade. Além disso, engendra um movimento de identificação entre o corpo da vítima e seu algoz que acarretará efeitos futuros. Em um segundo momento, o xamã e seus espíritos realizam a investigação da causa mortis o que poderá apontar a atuação de um feiticeiro. É na acusação de feitiço que a diferenciação atinge o interior do grupo consanguíneo, desestruturando-o, já que as tensões que surgem entre as famílias da vítima e do suposto feiticeiro podem provocar a fragmentação e a formação de grupos novos. A introdução da alteridade no centro do grupo reinaugura o movimento de hostilidade abdicado pelo ethos pacifista e desse modo impulsiona medidas agressivas em busca da vingança, seja através de novos feitiços, seja através da execução do responsável. A feitiçaria de vingança, utilizando o resíduo de identificação excessiva que une o corpo do feiticeiro ao da vítima, visa a causar danos ao agressor, agora ex-parente e não humano, e nesse movimento reafirma a identidade interna, humana, do grupo. O parentesco desfeito pelo feitiço é reafirmado pela busca por vingança em um novo ciclo de identificação e diferenciação que reposiciona os sujeitos na arena cosmopolítica. 
Uma breve passagem pelo contexto Yanomami nos permite vislumbrar outros métodos de administração da alteridade que relacionam, por meio de um constante desequilíbrio entre identificação e diferenciação, uma rede multicomunitária de alianças e inimizades. A partir da festa reahu o rito funerário, podemos observar alguns dos movimentos que consideramos até agora, de modo a reafirmar a importância vital da incorporação da alteridade - por meio dos idiomas do parentesco - nos processos de diferenciação em uma arena cosmopolítica que estende em muito as fronteiras do grupo. Albert (ALBERT, 1985) nos apresenta uma imagem da sociedade Yanomami que, para Viveiros de Castro, é "[...] o exemplar-tipo da teoria da afinidade potencial ou 'economia simbólica da alteridade"' (VIVEIROS DE CASTRO, 2014, p. 351).

Nesse esquema cosmopolítico, Albert observa a organização de uma estrutura concêntrica onde a variação de intensidade nas relações de hostilidade se desenrola entre o polo da afinidade virtual, onde se situam os inimigos reais, virtuais e desconhecidos, até o interior do grupo local, onde a afinidade é subsumida pela lógica do parentesco. O dinamismo entre esses polos é garantido pela introdução da figura do aliado não corresidente, que se posiciona como ponto intermediário, posição onde se pode vislumbrar a ambiguidade característica da relação de afinidade potencial. Essa relação, agenciada no ambiente controlado do rito, representa a duplicidade de sua condição através dos procedimentos que controlam a hostilidade guerreira e a identificação excessiva.

As festas reahu são promovidas em função do falecimento de um membro do grupo local, quando os parentes do morto convidam grupos aliados para a celebração do ritual funerário: a destruição do parentesco com o morto e a possibilidade de renovar os laços entre os grupos. Como aponta Albert (1985, p. 437), o ritual ultrapassa as funções funerárias de separação definitiva entre os vivos e os mortos, apesar de serem fundamentados por elas, exercendo um papel crucial nas negociações cosmopolíticas. É um acontecimento fundamental para a reprodução da vida Yanomami, tanto para a produção da identificação interna ao grupo quanto para afirmação, ou negação, de alianças 
intercomunitárias. Uma rápida descrição de três momentos dessa cerimônia nos permitirá observar a fabricação e destruição de relações de parentesco entre afins potenciais, como um método fundamental para gerir a administração da alteridade.

Após o falecimento do membro do grupo local os parentes se encarregam dos preparativos para a cerimônia. Uma grande quantidade de comida (sobretudo mingaus de banana e pupunha) é reservada para receber os visitantes. Os momentos que precedem o início da cerimônia são marcados pela tensão e expectativa por parte dos anfitriões que aguardam a chegada dos convidados, enquanto estes se preparam na floresta para surpreendê-los com sua dança praiai. A entrada cerimonial, a dança propriamente dita, encena uma hostilidade extravagante quando os convidados entram na casa coletiva de seus anfitriões brandindo armas de guerra e proclamando cantos e palavras de ordem de guerra e caça. A hostilidade é mascarada e dissimulada pelos movimentos jocosos e excessivos da dança praiai. Vemos, nessa encenação, a postura característica do processo de abertura à alteridade e o perigo que o envolve.

Em um segundo momento da cerimônia, após o arrefecimento dos ânimos exaltados pela chegada, acontece a distribuição de alimentos e a partilha entre anfitriões e convidados. Comer juntos é parte do movimento de identificação e assegura a aproximação pacífica entre afins potenciais. Porém, a identificação é novamente mascarada pelo tom agressivo que envolve essa dinâmica de troca. O alimento deve sempre ser ofertado por alguém do grupo oposto, e aqueles que dão e recebem se relacionam através dos termos de parentesco que indicam a afinidade atual: sobrinhos - ipa tarisia - cunhados - ipa xori/heri - e sogros - ipa xoae. Entretanto, as trocas procedem através de uma verdadeira competição onde a intenção professada pelas onomatopeias envolvidas no momento da oferta de alimento sugere um desafio com som de golpes, flechadas e tiros de armas de fogo (ALBERT, 1985, p. 454-455). Dessa forma, vemos aqui que o processo de identificação entre grupos locais aliados, engendrado pelo compartilhamento cerimonial de comida, precisa ser contraefetuado pela reafirmação da diferença entre corresidentes e não corresidentes. 
Um terceiro momento da cerimônia nos oferece mais um exemplo da relação ambígua entre aliados. Durante a dança hwakëmu é encenada a atualização da afinidade entre afins potenciais, por meio de uniões simbólicas que formam casais cerimoniais entre homens e mulheres de grupos não corresidentes, na contramão de sua preferência pela endogamia. Mesmo assim, apesar da simulação de um casamento improvável e da identificação fictícia entre os grupos criada no matrimônio, reafirma-se a necessidade da diferenciação, já que tais casamentos não costumam ser efetivados fora do contexto ritual. Por isso, tais encenações podem desenvolver hostilidades, nas tentativas de conquista das mulheres através de feitiços e do uso da força e de substancias mágicas. Assim, a incerteza da relação entre afins é sempre reafirmada. Podemos tomar como índice dessa instabilidade as emboscadas disfarçadas de convite para festas, ou a irrupção da violência por parte dos convidados durante as cerimônias, quando uma aliança pode ser quebrada pela violência e feitiçaria (ALBERT; KOPENAWA, 2015, p. 182) fazendo a inimizade voltar a caracterizar a relação entre afins.

Assim podemos ver por meio dos exemplos Yanomami, que as dinâmicas de parentesco agenciadas através da incorporação da alteridade prescindem da produção de rupturas para a sua reprodução e fundamento. Aqui começamos a delinear a conclusão do argumento exposto neste trabalho. Por meio de um sobrevoo por diferentes contextos amazônicos, buscamos enfatizar - na composição do "divíduo" ameríndio; nas relações interpessoais que reforçam a estrutura de parentesco; e nas redes intercomunitárias de alianças e inimizade que ligam os múltiplos níveis do cosmos - o eterno desequilíbrio no sistema de diferenciação e identificação, os motores da endoconsistência e do dinamismo reprodutivo da sociabilidade ameríndia.

\section{Conclusão}

Ao longo do percurso que fizemos até aqui, buscamos compreender os efeitos decorrentes dos mecanismos de diferenciação agenciados em contextos distintos, que atuam reintroduzindo a afinidade virtual contraefetuada pelas dinâmicas de identificação do parentesco, de modo 
a garantir a reprodução do sistema. A ambiguidade característica da relação com a alteridade radical - fonte de temor e desejo - engendra diferentes condicionamentos cosmopolíticos. É o medo dos Outros que engendra os processos de consanguinização na produção de um novo parente a partir do fundo de indiscernibilidade de onde emergem os sujeitos. Entretanto, essa figura da diferença, representada pelo afim virtual, é imprescindível, de modo que o processo de conjuração ativado pelo parentesco é impulsionado pela reintrodução de sua subjetividade externa, reintroduzindo incertezas e promovendo o dinamismo e o desequilíbrio criativo da estrutura.

Assim, podemos afirmar que os processos que produzem e desfazem o parentesco na Amazônia se relacionam em uma dinâmica de pressuposição recíproca, estando concomitantemente ativos em todo o trajeto percorrido entre os polos da afinidade e da consanguinidade, que não se anulam jamais. Representam assim uma dinâmica constante entre uma tendência e uma contratendência (VIVEIROS DE CASTRO, 2015, p. 130-131): a primeira operando o escalonamento progressivo que extrai diferenças na direção de concreções identitárias, enquanto a segunda reintroduz a diferença produzindo rupturas criativas.

Uma miríade de equivocidades compõe e transcende a paisagem Amazônica que adentramos. Personagens ambíguos - exemplificados aqui pelo cortador do cordão umbilical entre os Piro, o feiticeiro Aweti e o afim potencial Yanomami - agenciam sentimentos dúbios ao redor da identidade e da diferença. Por um lado, a identidade é desejada, mas é perigosa: em sua face positiva e controlada cria parentesco e coesão intra e intercomunitária, através das alianças que fundamenta; em sua face negativa, quando fabricada em excesso, torna os corpos vulneráveis e promove um esfriamento do sistema que o coloca em risco. De outro modo, a diferença é perigosa, mas é desejada: a diferenciação positiva possibilita as separações fundamentais, como a entre humanos e não humanos ou consanguíneos e afins, garantindo a reprodução e autonomia dos grupos; a diferenciação negativa é a que reintroduz alteridade no ambiente de identificação ativamente perseguido, produzindo todo tipo de fissuras. 
Dessa forma, o cromatismo generalizado que caracteriza a afinidade e consanguinidade - na fabricação da pessoa, da comunidade e das alianças interespecíficas e intercomunitárias - nos aponta a direção dos fundamentos ontológicos de uma metafísica contra-oUm. A impossibilidade da cristalização dos estatutos e fronteiras que definem o sujeito, o grupo e o conjunto multicomunitário conjura a sobrecodificação transcendente estabilizada em uma estrutura englobante que homogeneíze verticalmente o socius, ao mesmo tempo em que oferece uma negação radical do solipsismo, da solidão, da existência autorreferenciada e antirrelacional.

Se a imanência do inimigo desenha uma cartografia afetiva onde o medo se faz sempre presente, esse não é, porém, um medo hobbesiano - que motiva a conjuração das fissuras e a demanda por sobrecodificação. A indiscernibilidade desse Outro-referencial onipresente indica que a iminência da captura é já a impossibilidade do Um: a captura opera a redistribuição quantitativa e qualitativa das pessoas - menos um Aweti, mais um kat - em uma economia cósmica de afetos transespecíficos composta por uma rede de coletivos descentrados, distribuídos pelos patamares cósmicos (VIVEIROS DE CASTRO, 2015, p. 187). É a metafísica da predação que articula esses planos, o que podemos observar pelo mesmo idioma que traduz o ato da incorporação da afinidade virtual nos âmbitos da caça, da guerra, da feitiçaria e do xamanismo: devorar diferenças para produzir as identidades cujo resíduo insistente produzirá novas diferenças. Essa dinâmica em eterno desequilíbrio é o que garante o dinamismo produtivo e a endoconsistência do socius ameríndio. Assim:

Reconhecer a produção de diferença engendrada no processo cotidiano de criação de identidade nos permite entender, desde um ponto de partida complemente distinto, aquilo que Clastres apontou como filosofia contrao-Estado das sociedades amazônicas. (VANZOLINI, 2013, p. 362)

O parentesco é posterior ao "meta-estado de hostilidade virtual" no qual a afinidade é o idioma, e o contraefetua por meio da fabricação de parentes. Esse procedimento se insere em um agenciamento 
cosmopolítico no qual o problema é sempre a administração da alteridade, gerindo os fluxos e forças negativos e positivos que interligam os afins virtuais. É assim, através da análise construída nesse trabalho, que podemos argumentar com Viveiros de Castro que "a afinidade virtual pertence à guerra antes que ao parentesco" e a que "aliança intensiva amazônica é uma aliança contra o Estado" (VIVEIROS DE CASTRO, 2015, p. 206). Desse modo, podemos concluir que o parentesco só é produzido para ser desfeito ou recusado, pois a aliança é um "mal necessário" em uma estrutura fundamentada na alteridade. Se a identidade é um caso particular da diferença; se a amizade nasce sob o signo-referencial da inimizade - "[...] não houvesse inimigos, seria preciso inventá-los [...]" (CLASTRES, 2014, p. 250) - é porque o movimento centrífugo é primeiro nos termos de uma filosofia contrao-Um.

\section{Agradecimentos}

Agradeço a Eduardo Viveiros de Castro e Nicole Soares-Pinto pelo curso "Organização Social e Parentesco" ministrado em 2016/1 no PPGAS/MN, que inspirou este artigo.

\section{Referências}

ALBERT, Bruce. Temps du sang, temps des cendres. Représentation de la maladie, espace politique et système ritual chez les Yanomami du sud-est (Amazonie brésilienne). 1985. Tese (Doutorado) - Universidade de Paris X, Nanterre, 1985.

ALBERT, Bruce; KOPENAWA, Davi. A queda do céu: palavras de um xamã yanomami. São Paulo, SP: Companhia das Letras, 2015.

CLASTRES, Pierre. Arqueologia da Violência: pesquisas de antropologia política. 3. ed. São Paulo: Cosac Naify, 2014.

DANOWSKI, Déborah; VIVEIROS DE CASTRO, Eduardo. Há mundo por vir? Ensaio sobre os fins e os medos. Florianópolis: Cultura e Barbárie; Instituto Socioambiental, 2014.

GOW, Peter. O Parentesco como Consciência Humana: o Caso dos Piro.

Mana: Estudos de Antropologia Social, [S.l.], v. 3, v. 2, p. 39-66, 1997. 
LÉVI-STRAUSS, Claude. As Estruturas Elementares do Parentesco. Tradução de Mariano Ferreira. Petrópolis: Vozes, 1982.

OVERING, Joanna. Elogio do Cotidiano: a confiança e a arte da vida social em uma comunidade amazônica. Mana: Estudos de Antropologia Social, [S.l.], v. 5, n. 1, p. 81-108, 1999.

VANZOLINI, Marina. Ser e não ser gente: dinâmicas da feitiçaria no Alto Xingu. Mana: Estudos de Antropologia Social, [S.l.], v. 19, n. 2, p. 341370, 2013.

VANZOLINI, Marina. A flecha do ciúme: o parentesco e seu avesso segundo os Aweti do Alto Xingu. São Paulo: Terceiro Nome, 2015.

VILAÇA, Aparecida. Making Kin Out Of Others in Amazonia. Royal Anthropological Institute, [S.l.], v. 8, p. 347-365, 2002.

VIVEIROS DE CASTRO, Eduardo. O medo dos Outros. Revista de Antropologia USP, São Paulo, v. 54, n. 2, p. 885-917, 2011.

VIVEIROS DE CASTRO, Eduardo. Metafísicas Canibais: elementos para uma antropologia pós-estrutural. Rio de Janeiro: Cosac Naify, 2015.

VIVEIROS DE CASTRO, Eduardo. A inconstância da alma selvagem: e outros ensaios de antropologia. São Paulo: Cosac Naify, 2013.

VIVEIROS DE CASTRO, Eduardo. Posfácio. O Intempestivo, ainda. In: CLASTRES, Pierre. Arqueologia da Violência: pesquisas de antropologia política. 3. ed. São Paulo: Cosac Naify, 2014. p. 299-366.

Recebido em 03/05/2017

Aceito em 26/09/2019

\section{Marcelo Moura Silva}

Doutorando em Antropologia Social. PPGAS - Museu Nacional (UFRJ), Rio de Janeiro. Quinta da Boa Vista, s/n, São Cristóvão, Rio de Janeiro. CEP: 20940-040. E-mail: mouramarcelosilva@gmail.com 